Article

\title{
Molecular Analysis of Retrogradation of Corn Starches
}

\author{
Marek Sikora ${ }^{1}$, Magdalena Krystyjan ${ }^{1}$, Anna Dobosz ${ }^{1}$, Piotr Tomasik ${ }^{2}$, Katarzyna Walkowiak ${ }^{3}$, \\ Lukasz Masewicz $^{3}$, Przemysław Lukasz Kowalczewski ${ }^{4}$ (D) and Hanna Maria Baranowska ${ }^{3, *(D)}$ \\ 1 Department of Carbohydrates Technology, University of Agriculture in Kraków, 122 Balicka Street, \\ 30-149 Kraków, Poland; rrsikora@cyf-kr.edu.pl (M.S.); magdalena.krystyjan@urk.edu.pl (M.K.); \\ anna.dobosz88@gmail.com (A.D.) \\ 2 Nantes Nano Nanotechnological Systems, 21 Dolne Młyny Street, 50-700 Bolesławiec, Poland; \\ rrtomasi@cyf-kr.edu.pl \\ 3 Department of Physics and Biophysics, Poznań University of Life Sciences, 38/42 Wojska Polskiego Street, \\ 60-637 Poznań, Poland; katarzyna.walkowiak@up.poznan.pl (K.W.); lukasz.masewicz@up.poznan.pl (Ł.M.) \\ 4 Institute of Food Technology of Plant Origin, Poznań University of Life Sciences, 31 Wojska Polskiego Street, \\ 60-624 Poznań, Poland; przemyslaw.kowalczewski@up.poznan.pl \\ * Correspondence: hanna.baranowska@up.poznan.pl
}

Received: 20 September 2019; Accepted: 24 October 2019; Published: 27 October 2019

check for updates

\begin{abstract}
Changes of the molecular dynamics of water in 5\% corn starch pastes and 5\% systems composed of starch and non-starchy hydrocolloid were studied during short and long term retrogradation. Low Field NMR was used to record mean correlation times $\left(\tau_{\mathrm{c}}\right)$ of water molecules. This molecular parameter reflects the rotation of water molecules within the network of paste. Starches of different amylose and amylopectin content were selected for this study. Comparison of the changes of $\tau_{\mathrm{c}}$ shows how particular polymers bind water molecules. During 90 days of storage, over $50 \%$ increase in mean correlation time was recorded in pastes of starches with high amylose content. This suggests that the formation of polymeric network is controlled by amylose to which water is binding. Amylopectin was found to influence the mobility of water in the pastes to a lesser extent with changes in mean correlation times of approximately 10-15\% over 90 days. On retrogradation, amylopectin, Arabic and xanthan gums hindered the formation of solid phase structures. Guar gum evoked an increase in mean correlation times of approximately $40-50 \%$ during the prolonged process of changes of the molecular dynamics of water. This indicates continued expansion of the polymeric network. Mean correlation time available from spin-lattice and spin-spin relaxation times can be useful in the analysis of the rotational vibrations of the water molecules in biopolymeric structures.
\end{abstract}

Keywords: amylose; amylopectin; plant gums; relaxometry; spin-lattice relaxation times; spin-spin relaxation times

\section{Introduction}

Starch is a naturally abundant polymer produced by many plants as a means of energy storage. It has been used for years not only in the production of food [1-3] but also in other industries [4,5]. In contrast to several other starches, corn starches gelatinize in a specific, more complex manner [6-9]. Their retrogradation is also unique. The short-term retrogradation of normal [8,10-14] and waxy [15-19] corn starches has been fairly well described. Fisher and Thompson [20] and Liu et al. [21] showed that retrogradation was controlled to the greatest extent by the residual crystalline structures of double helices of amylopectin chains in corn starch. Considerable attention was paid to the possibility of controlling retrogradation of corn starch pastes with selected additives such as galactomannans and citric acid [22], porcine plasma protein hydrolyzates [23,24], various disaccharides [25] and branched 
limit dextrins [26]. Promising results encouraged us to study the effect of Arabic, guar and xanthan gums on short- and long-term retrogradation of corn starches.

Our former papers presented the results of studies on short- and long-term retrogradation of potato starches of various amylose content [27] and the effects of addition of non-starchy polysaccharide hydrocolloids on the process [28]. The results of ${ }^{1} \mathrm{H}$ NMR analyzes of retrogradation in pastes of these starches blended with non-starchy polysaccharide hydrocolloids were presented in our recent paper [29]. The latter documented that short- and long-term retrogradation was promoted by amylose and accelerated with its increasing content in pastes of two normal potato starches with different amylose content and one waxy potato starch. Arabic, guar or xanthan gums retarded retrogradation of starch pastes. The effect of these non-starchy polysaccharide hydrocolloids, particularly upon long-term retrogradation, was a result of changes in molecular properties of water.

In this paper the details of retrogradation over a prolonged storage of two normal and one waxy corn starch are presented. Based on hardening and syneresis of the starch gels, it could be stated that retrogradation was proportional to the concentration of starch and the content of amylose. A molecular analysis of the retrogradation process in corn starches blended with three non-starchy polysaccharide hydrocolloids was also performed. The analysis was based on measuring ${ }^{1} \mathrm{H}$ NMR spin-lattice and spin-spin relaxation times in studied pastes as retrogradation progressed within the period of up to 90 days. The obtained data was than interpreted in terms of the changes of water status. Since the relaxation times are macroscopic parameters [30-32], mean correlation times that have microscopic character [33-35] were employed.

Selection of starch for this study as well as concentration of the pastes and non-starchy hydrocolloids in binary mixtures was based on our recent studies. Pastes of corn starch in the concentration of $5 \%$ and so concentrated binary pastes with selected non-starchy hydrocolloids are used in practice as thickeners for controlling the rheological properties and texture of food products [36-44].

\section{Materials and Methods}

\subsection{Materials}

Normal corn starch (NCS) of 20.48\% amylose, Hylon corn starch (HCS) of 49.75\% amylose and waxy corn starch (WCS) of $0.75 \%$ amylose were purchased from Cargill Sp. z.o.o. (Warsaw, Poland). Arabic (AG), guar (GG) and xanthan (XG) gums were purchased from Sigma Aldrich (St. Louis, MO, USA).

\subsection{Sample Preparation}

Pastes composed of $5 \mathrm{wt} \%$ starch or $4.8 \mathrm{wt} \%$ starch with $0.2 \mathrm{wt} \%$ hydrocolloid were by heating for $30 \mathrm{~min}$ at $90{ }^{\circ} \mathrm{C}$ with gentle stirring. Resulting hot pastes $\left(0.2 \mathrm{~cm}^{3}\right)$ were passed into measurement vials, sealed with parafilm and allowed to cool to room temperature. Thermally equilibrated samples in the measurement viols were then cooled to $5^{\circ} \mathrm{C}$ in an ice bath.

\subsection{Relaxation Time Measurements}

Measurements of relaxation times were taken after 1,2,10, 30 and 90 days of storage at $5{ }^{\circ} \mathrm{C}$. The spin-lattice $\left(T_{1}\right)$ and spin-spin $\left(T_{2}\right)$ relaxation times were measured at $15 \mathrm{MHz}$ with PS15T impulse ${ }^{1} \mathrm{H}$ NMR spectrometer (ELLAB, Poznań, Poland) equipped with an integral temperature control system. Prior to the experiments, samples placed in the spectrometer were allowed to heat to $20^{\circ} \mathrm{C}$.

The inversion-recovery $(\pi-\mathrm{t}-\pi / 2)$ impulse sequence [45] was applied for taking $T_{1}$ relaxation times. Distances between impulses $(t)$ were changed within the range from 100 to $1000 \mathrm{~ms}$ at the $20 \mathrm{~s}$ repetition time. Each time, 32 FID signals and 119 points from each FID signal were collected.

Calculations of the spin-lattice relaxation time values were performed with CracSpin software (Jagiellonian University, Cracow, Poland) [46] using a "spin grouping" approach. Marquardt's method of minimization was applied for fitting multiexponential decays. The accuracy of the relaxation parameters 
was determined and standard deviations were calculated. Time changes of the current value of the FID signal amplitude in the employed frequency of impulses were described by Equation (1):

$$
M_{\mathrm{Z}}(t)=M_{0}\left(1-2 e^{\frac{-t}{T_{1}}}\right)
$$

where: $M_{\mathrm{z}}(t)$ is the actual magnetization value, $M_{0}$ is the equilibrium magnetization value, $t$ is the distance between impulses and $T_{1}$ is the spin-lattice relaxation time.

Monoexponential magnetization recovery indicated that the system relaxed within one $T_{1}$ spin-lattice relaxation time.

Measurements of the $T_{2}$ spin-spin relaxation times were taken using the pulse train of the Carr-Purcell-Meiboom-Gill spin echoes $\left(\pi / 2-\mathrm{TE} / 2-(\pi)_{n}\right)[47,48]$. The distance between $\pi$ (TE) impulses was $2 \mathrm{~ms}$ and the repetition time was $15 \mathrm{~s}$. The number of spin echoes $(n)$ was 100 . Tree accumulation signals were employed.

The calculation of spin-spin relaxation time values was based on adjustment of the values of echo amplitudes to Equation (2) [49,50]:

$$
M_{\mathrm{x}, \mathrm{y}}(T E)=M_{0} \sum_{i=1}^{n} p_{i} e^{\frac{-T E}{T_{2 i}}},
$$

where: $M_{\mathrm{x}, \mathrm{y}}(T E)$ is the echo amplitude; $M_{\mathrm{o}}$ is the equilibrium amplitude; TE is the distance between $\pi$ impulses and $p_{i}$ is the fraction of protons relaxing with the $T_{2 i}$ spin-spin relaxation time.

The calculations were performed with dedicated software using a non-linear least-square algorithm. Standard deviation was used to determine the accuracy of the relaxation parameters.

\subsection{Statistical Analysis}

One-way analysis of variance was performed independently for each dependent variable. Post-hoc Tukey HSD (honest significant difference) multiple comparison tests were used to identify statistically homogeneous subsets at $\alpha=0.05$. Statistical analysis of the data was performed with Statistica 13 (Dell Software Inc., Round Rock, TX, USA) software.

\section{Results and Discussion}

In Tables 1-4 the recorded spin-lattice, $T_{1}$, and spin-spin, $T_{2}$, relaxation times were collected. Their values taken in the two first days of experiments were common for $5 \%$ pastes of normal starches (see, for instance, Glöggler et al. [51]). No essential time-dependent changes of these parameters were observed within first 10 days of storage. After a 30 day storage a two-fold decrease in $T_{2}$ was observed, whereas values of $T_{1}$ declined just after 90 days. Hence, one could assume that up to 30 days water in NCS was bound in a stable manner. Initially, changes were associated with an increase in the role of spin-spin interactions between the protons of the starch chains. Long spin-lattice relaxation times indicated a large quantity of bulk water in the system. A decrease in both relaxation times in pastes of NCS after 90 days pointed to an increase in the amount of bound water. An ordered macroscopic structure was formed in which water molecules had limited mobility. One could deduce that bound water molecules limited mobility.

In the initial storing period, $T_{1}$ values for pastes of NCS and WCS were close to one another indicating a similar bulk to bound water ratio in both pastes (Table 1). However, $T_{2}$ values in both cases were significantly distinct from each other. In pastes of WCS, $T_{2}$ were about twice as high as in pastes of NCS pointing to much lower availability of water in the latter starch and water present in that paste constituted mainly the bulk fraction. Both relaxation times changed only slightly during 30 days of storage. After 90 days, $T_{2}$ was shortened as a result of the structural ordering in the pastes. Pastes of HCS showed a single $T_{1}$ component and two $T_{2}$ components. This finding is atypical for biopolymer gels. Both components of $T_{2}$ were determined by water dynamics in the bulk $\left(T_{21}\right)$ and 
bound $\left(T_{2 \mathrm{~s}}\right)$ fractions. Two fractions of water characterized by different $T_{2}$ are encountered in tissue systems $[30,52]$ and emulsions $[53,54]$. HCS contained mainly linear polymeric chains. The occurrence of two $T_{2}$ components might have been promoted by a relatively low content of starch with respect to the content of water. Hence, in the pastes, protons relaxing with a relatively short time (150-250 ms) constituted a fraction of protons of a low mobility. Likely, they were directly bound to starch. Fraction of protons of $T_{21}$ was characterized by high relaxation times. Thus, these protons belonged to a water fraction, which did not interact with the paste network. Based on the $T_{21}$ criterion this water could be called the free water fraction. Time dependent variations of $T_{1}$ and both components of $T_{2}$ indicated that significant changes observed in pastes stored for 1 and 2 days might be related to short-time retrogradation. Significant shortening of $T_{1}$ accompanied by the extension of $T_{2}$ could suggest an impact of the presence of amylopectin in the pastes. Short chains involved in the formation of the network could control the amount of free water without limiting its mobility. On prolonged storage, relaxation parameters changed non-monotonously. These changes resulted from the interactions of water with the polymer. An essential increase in the $T_{1}$ values that was observed on the 10th day of storage could be due to reorganization of the water macrostructure evoked by conformational changes of amylase. The $p_{i}$ parameter (Equation (2)) that reflects the participation of protons of particular water fractions in the relaxation varied only by $10 \%$. Therefore, its significance in the analysis of the changes of the molecular dynamics of water within $5 \%$ starch pastes was limited.

Table 1. Mean relaxation times of spin-lattice $T_{1}$ and spin-spin $T_{2}$, in stored corn starch pastes.

\begin{tabular}{cccccccc}
\hline $\begin{array}{c}\text { Storage } \\
\text { Time (days) }\end{array}$ & \multicolumn{2}{c}{ NCS } & \multicolumn{2}{c}{ WCS } & HCS \\
\cline { 2 - 7 } & $\boldsymbol{T}_{\mathbf{1}} \mathbf{( \mathbf { m s } )}$ & $\boldsymbol{T}_{\mathbf{2}} \mathbf{( m s )}$ & $\boldsymbol{T}_{\mathbf{1}}(\mathbf{m s})$ & $\boldsymbol{T}_{\mathbf{2}}(\mathbf{m s})$ & $\boldsymbol{T}_{\mathbf{1}}(\mathbf{m s})$ & $\boldsymbol{T}_{\mathbf{2}} \mathbf{s}^{*}(\mathbf{m s})$ & $\boldsymbol{T}_{\mathbf{2}} \mathbf{~}^{* *}(\mathbf{m s})$ \\
\hline 1 & $1663 \pm 5^{\mathrm{a}}$ & $471 \pm 3^{\mathrm{a}}$ & $1612 \pm 5^{\mathrm{d}}$ & $935 \pm 5^{\mathrm{a}}$ & $1401 \pm 4^{\mathrm{b}}$ & $220 \pm 1^{\mathrm{b}}$ & $785 \pm 7^{\mathrm{e}}$ \\
2 & $1569 \pm 4^{\mathrm{b}}$ & $467 \pm 5^{\mathrm{b}}$ & $1650 \pm 4^{\mathrm{c}}$ & $864 \pm 4^{\mathrm{c}}$ & $1257 \pm 3^{\mathrm{d}}$ & $239 \pm 4^{\mathrm{a}}$ & $966 \pm 2^{\mathrm{b}}$ \\
10 & $1557 \pm 8^{\mathrm{b}}$ & $468 \pm 4^{\mathrm{b}}$ & $1687 \pm 8^{\mathrm{b}}$ & $876 \pm 6^{\mathrm{b}}$ & $1404 \pm 4^{\mathrm{b}}$ & $172 \pm 3^{\mathrm{c}}$ & $896 \pm 4^{\mathrm{d}}$ \\
30 & $1559 \pm 7^{\mathrm{b}}$ & $253 \pm 3^{\mathrm{c}}$ & $1697 \pm 4^{\mathrm{a}}$ & $874 \pm 3^{\mathrm{b}}$ & $1385 \pm 4^{\mathrm{c}}$ & $146 \pm 2^{\mathrm{e}}$ & $922 \pm 9^{\mathrm{c}}$ \\
90 & $1280 \pm 6^{\mathrm{c}}$ & $186 \pm 3^{\mathrm{d}}$ & $1614 \pm 4^{\mathrm{d}}$ & $563 \pm 8^{\mathrm{c}}$ & $1411 \pm 8^{\mathrm{a}}$ & $156 \pm 5^{\mathrm{d}}$ & $1010 \pm 2^{\mathrm{a}}$ \\
\hline
\end{tabular}

* For bound water fraction. ${ }^{* *}$ For bulk water fraction. Mean values \pm SD with different letters in the columns are significantly different at $\alpha=0.05$. NCS-normal corn starch; WCS—waxy corn starch; HCS-Hylon corn starch.

An increase in the turbidity and eventual precipitation that was observed in all the samples indicated that amylose molecules were unstable, which led to their retrogradation. Retrogradation was a result of the shrinkage of amylose molecules caused by a decrease in the kinetic energy and Brownian motion of the polymer and water molecules. This shrinkage promoted intra- and inter-molecular hydrogen bonding between both the hemiacetal oxygen atom and the adjacent OH-6 of the D-glucopyranosyl residues, and the O-6 and OH-2 of D-glycopyranosyl residues of different molecules. Such bonding facilitated the precipitation of the amylose molecules from the aqueous medium.

Tables 2-4 contain values of $T_{1}$ and $T_{2}$ recorded for binary pastes of corn starches with AG, GG and XG, respectively. For binary pastes of HCS invariantly two components of $T_{2}$ were observed, which meant that these pastes contained two independent water fractions. Time dependent changes of the relaxation parameters were perturbed by admixed gums but trends of the changes remained the same as in hydrocolloid free pastes. AG limited the content of bulk water fraction while causing the content of bound water fraction to increase. Thus, AG improved water binding in the biopolymer network.

$T_{1}$ values for binary pastes of NCS with GG resembled these for the binary NCS + AG pastes. Both gums influenced water binding in the pastes to the same extent (Tables 2 and 3 ). However, $T_{2}$ in the HCS + GG pastes was shorter than that in the HCS + AG pastes. This observation indicates that water mobility was limited to a greater extent in network that contained GG. $T_{2}$ for the WCS pastes reflected the mobility of the bound water fraction. The bulk water fraction in the binary WCS + GG pastes had better opportunity for molecular movements than it had in the WCS + AG pastes. 
Table 2. Mean relaxation times of spin-lattice, $T_{1}$ and spin-spin, $T_{2}$, in stored corn starch-Arabic gum binary pastes.

\begin{tabular}{cccccccc}
\hline \multirow{2}{*}{$\begin{array}{c}\text { Storage } \\
\text { Time (days) }\end{array}$} & \multicolumn{2}{c}{ NCS + AG } & \multicolumn{2}{c}{ WCS + AG } & HCS + AG \\
\cline { 2 - 7 } & $\boldsymbol{T}_{\mathbf{1}}(\mathbf{m s})$ & $\boldsymbol{T}_{\mathbf{2}}(\mathbf{m s})$ & $\boldsymbol{T}_{\mathbf{1}}(\mathbf{m s})$ & $\boldsymbol{T}_{\mathbf{2}}(\mathbf{m s})$ & $\boldsymbol{T}_{\mathbf{1}}(\mathbf{m s})$ & $\boldsymbol{T}_{\mathbf{2}} \mathbf{s}^{*}(\mathbf{m s})$ & $\boldsymbol{T}_{\mathbf{2}} \mathbf{l}^{* *}(\mathbf{m s})$ \\
\hline 1 & $1507 \pm 4^{\mathrm{a}}$ & $438 \pm 4^{\mathrm{b}}$ & $1621 \pm 4^{\mathrm{b}}$ & $840 \pm 5^{\mathrm{c}}$ & $1296 \pm 2^{\mathrm{b}}$ & $257 \pm 4^{\mathrm{a}}$ & $1204 \pm 4^{\mathrm{a}}$ \\
2 & $1511 \pm 2^{\mathrm{a}}$ & $455 \pm 5^{\mathrm{a}}$ & $1613 \pm 4^{\mathrm{c}}$ & $904 \pm 5^{\mathrm{a}}$ & $1256 \pm 2^{\mathrm{c}}$ & $162 \pm 4^{\mathrm{c}}$ & $808 \pm 5^{\mathrm{e}}$ \\
10 & $1483 \pm 4^{\mathrm{b}}$ & $419 \pm 5^{\mathrm{c}}$ & $1608 \pm 5^{\mathrm{d}}$ & $871 \pm 4^{\mathrm{b}}$ & $1339 \pm 1^{\mathrm{a}}$ & $225 \pm 3^{\mathrm{b}}$ & $1138 \pm 5^{\mathrm{b}}$ \\
30 & $1458 \pm 5^{\mathrm{c}}$ & $277 \pm 4^{\mathrm{d}}$ & $1635 \pm 2^{\mathrm{a}}$ & $843 \pm 5^{\mathrm{c}}$ & $1292 \pm 4^{\mathrm{b}}$ & $129 \pm 4^{\mathrm{d}}$ & $849 \pm 4^{\mathrm{d}}$ \\
90 & $1365 \pm 1^{\mathrm{d}}$ & $224 \pm 7^{\mathrm{e}}$ & $1549 \pm 3^{\mathrm{e}}$ & $790 \pm 3^{\mathrm{d}}$ & $1260 \pm 2^{\mathrm{c}}$ & $165 \pm 5^{\mathrm{c}}$ & $1018 \pm 7^{\mathrm{c}}$ \\
\hline
\end{tabular}

${ }^{*}$ For bound water fraction. ${ }^{* *}$ For bulk water fraction. Mean values \pm SD with different letters in the columns are significantly different at $\alpha=0.05$. NCS + AG—normal corn starch with Arabic gum; WCS + AG—waxy corn starch with Arabic gum; HCS + AG-Hylon corn starch with Arabic gum.

Table 3. Mean relaxation times of spin-lattice, $T_{1}$ and spin-spin, $T_{2}$, in stored corn starches-guar gum binary pastes.

\begin{tabular}{cccccccc}
\hline \multirow{2}{*}{$\begin{array}{c}\text { Storage } \\
\text { Time (days) }\end{array}$} & \multicolumn{2}{c}{ NCS + GG } & \multicolumn{2}{c}{ WCS + GG } & \multicolumn{3}{c}{ HCS + GG } \\
\cline { 2 - 7 } & $\boldsymbol{T}_{\mathbf{1}}(\mathbf{m s})$ & $\boldsymbol{T}_{\mathbf{2}}(\mathbf{m s})$ & $\boldsymbol{T}_{\mathbf{1}}(\mathbf{m s})$ & $\boldsymbol{T}_{\mathbf{2}}(\mathbf{m s})$ & $\boldsymbol{T}_{\mathbf{1}}(\mathbf{m s})$ & $\boldsymbol{T}_{\mathbf{2}} \mathbf{s}^{*}(\mathbf{m s})$ & $\boldsymbol{T}_{\mathbf{2}} \mathbf{l}^{* *}(\mathbf{m s})$ \\
\hline 1 & $1522 \pm 2^{\mathrm{a}}$ & $470 \pm 4^{\mathrm{a}}$ & $1700 \pm 3^{\mathrm{ab}}$ & $871 \pm 5^{\mathrm{a}}$ & $1228 \pm 2^{\mathrm{c}}$ & $246 \pm 5^{\mathrm{a}}$ & $1142 \pm 4^{\mathrm{a}}$ \\
2 & $1415 \pm 2^{\mathrm{c}}$ & $443 \pm 5^{\mathrm{b}}$ & $1709 \pm 3^{\mathrm{a}}$ & $811 \pm 5^{\mathrm{c}}$ & $1194 \pm 2^{\mathrm{d}}$ & $136 \pm 5^{\mathrm{d}}$ & $778 \pm 5^{\mathrm{d}}$ \\
10 & $1379 \pm 4^{\mathrm{d}}$ & $446 \pm 7^{\mathrm{b}}$ & $1690 \pm 4^{\mathrm{b}}$ & $840 \pm 7^{\mathrm{b}}$ & $1298 \pm 4^{\mathrm{b}}$ & $218 \pm 7^{\mathrm{b}}$ & $989 \pm 4^{\mathrm{c}}$ \\
30 & $1462 \pm 2^{\mathrm{b}}$ & $355 \pm 7^{\mathrm{c}}$ & $1666 \pm 3^{\mathrm{c}}$ & $692 \pm 5^{\mathrm{d}}$ & $1346 \pm 3^{\mathrm{a}}$ & $136 \pm 8^{\mathrm{d}}$ & $1017 \pm 4^{\mathrm{b}}$ \\
90 & $1367 \pm 1^{\mathrm{e}}$ & $267 \pm 5^{\mathrm{d}}$ & $1596 \pm 3^{\mathrm{d}}$ & $499 \pm 6^{\mathrm{e}}$ & $1300 \pm 3^{\mathrm{b}}$ & $145 \pm 5^{\mathrm{c}}$ & $994 \pm 2^{\mathrm{c}}$ \\
\hline
\end{tabular}

* For bound water fraction. ${ }^{* *}$ For bulk water fraction. Mean values \pm SD with different letters in the columns are significantly different at $\alpha=0.05$. NCS + AG—normal corn starch with guar gum; WCS + AG—waxy corn starch with guar gum; $\mathrm{HCS}+\mathrm{AG}-$ Hylon corn starch with guar gum.

An admixture of XG to corn starch pastes of NCS and WCS resulted in negligible changes of both relaxation times (Table 4). Thus, on storage, water in both these systems did not change its molecular properties. Binary WCS-XG paste differed in this respect from the hydrocolloid-free WCS paste. Amount of the bulk water fraction compared to the amount of bound water fraction was reduced what was manifested by longer $T_{1}$. The water in bound fraction was more mobile whereas the water in bulk fraction faced strong limitations. Hence, one could deduce that XG did not interact with WCS and observed mobility limitations were caused by the hydrocolloid.

Table 4. Mean relaxation times of spin-lattice $T_{1}$ and spin-spin $T_{2}$ in stored corn starches-xanthan gum binary pastes.

\begin{tabular}{cccccccc}
\hline \multirow{2}{*}{$\begin{array}{c}\text { Storage } \\
\text { Time (days) }\end{array}$} & \multicolumn{2}{c}{ NCS + XG } & \multicolumn{2}{c}{ WCS + XG } & \multicolumn{3}{c}{ HCS + XG } \\
\cline { 2 - 7 } & $\boldsymbol{T}_{\mathbf{1}}(\mathbf{m s})$ & $\boldsymbol{T}_{\mathbf{2}}(\mathbf{m s})$ & $\boldsymbol{T}_{\mathbf{1}}(\mathbf{m s})$ & $\boldsymbol{T}_{\mathbf{2}}(\mathbf{m s})$ & $\boldsymbol{T}_{\mathbf{1}}(\mathbf{m s})$ & $\boldsymbol{T}_{\mathbf{2}} \mathbf{s}^{*}(\mathbf{m s})$ & $\boldsymbol{T}_{\mathbf{2}} \mathbf{1}^{* *}(\mathbf{m s})$ \\
\hline 1 & $1558 \pm 4^{\mathrm{d}}$ & $869 \pm 5^{\mathrm{ab}}$ & $1574 \pm 2^{\mathrm{e}}$ & $871 \pm 4^{\mathrm{ab}}$ & $1362 \pm 2^{\mathrm{b}}$ & $358 \pm 2^{\mathrm{a}}$ & $4^{\mathrm{b}} \pm 6^{\mathrm{c}}$ \\
2 & $1587 \pm 4^{\mathrm{c}}$ & $839 \pm 4^{\mathrm{a}}$ & $1597 \pm 2^{\mathrm{c}}$ & $877 \pm 5^{\mathrm{a}}$ & $1225 \pm 2^{\mathrm{d}}$ & $298 \pm 3^{\mathrm{b}}$ & $459 \pm 5^{\mathrm{e}}$ \\
10 & $1642 \pm 5^{\mathrm{b}}$ & $877 \pm 4^{\mathrm{b}}$ & $1612 \pm 4^{\mathrm{b}}$ & $865 \pm 4^{\mathrm{b}}$ & $1337 \pm 1^{\mathrm{c}}$ & $225 \pm 2^{\mathrm{c}}$ & $801 \pm 5^{\mathrm{a}}$ \\
30 & $1657 \pm 4^{\mathrm{a}}$ & $710 \pm 6^{\mathrm{c}}$ & $1677 \pm 2^{\mathrm{a}}$ & $842 \pm 4^{\mathrm{c}}$ & $1388 \pm 4^{\mathrm{a}}$ & $153 \pm 5^{\mathrm{e}}$ & $617 \pm 4^{\mathrm{b}}$ \\
90 & $1542 \pm 7^{\mathrm{cd}}$ & $698 \pm 5^{\mathrm{bc}}$ & $1582 \pm 3^{\mathrm{d}}$ & $653 \pm 5^{\mathrm{d}}$ & $1225 \pm 4^{\mathrm{d}}$ & $183 \pm 2^{\mathrm{d}}$ & $472 \pm 5^{\mathrm{d}}$ \\
\hline
\end{tabular}

${ }^{*}$ For bound water fraction. ${ }^{* *}$ For bulk water fraction. Mean values \pm SD with different letters in the columns are significantly different at $\alpha=0.05$. NCS + AG—normal corn starch with xanthan gum; WCS + AG—waxy corn starch with xanthan gum; HCS + AG-Hylon corn starch with xanthan gum.

Results of the relaxation time measurements showed a path of changing relations between bulk and bound water. Mean correlation time was used to describe the molecular dynamics of water. Time dependent changes of that parameter in starch pastes free of hydrocolloids under study are presented in Figure 1. 


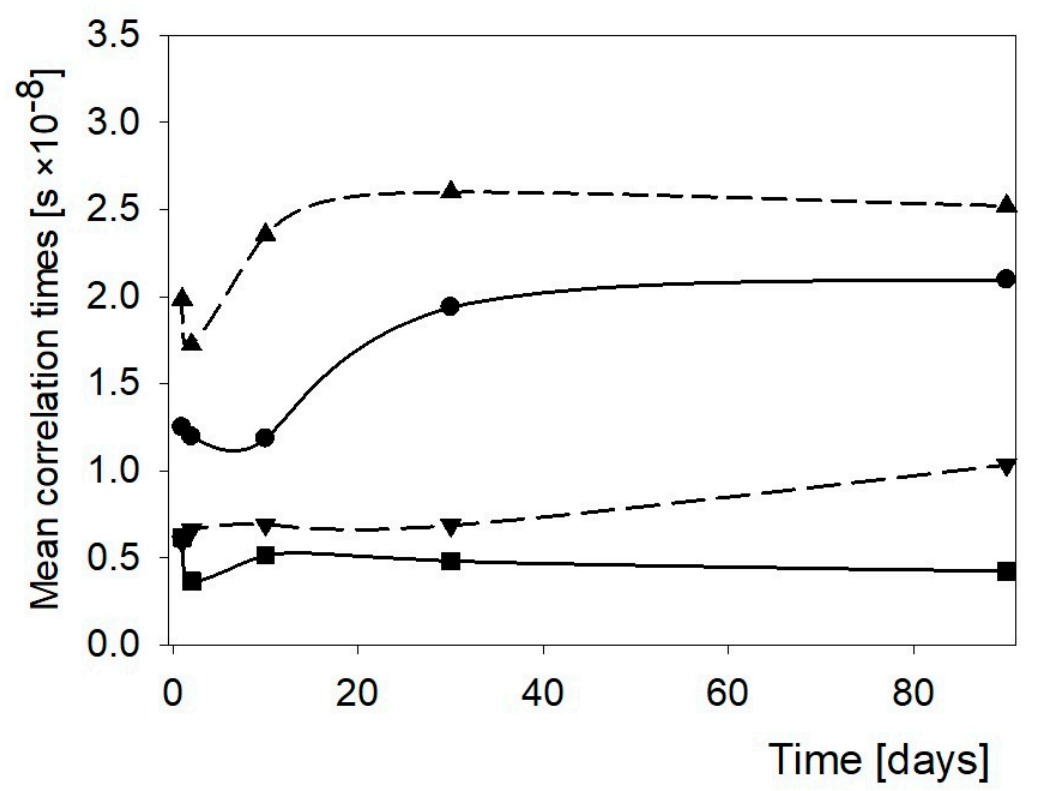

Figure 1. Changes of the mean correlation times in corn starch gels. and $\mathbf{m C S}$ (1-fraction).

As macroscopic parameters, relaxation times reflected mutual relations between bulk and bound water in the system $\left(T_{1}\right)$ and its mobility $\left(T_{2}\right)$.

Solution of Equations (3) and (4) [32] provided mean correlation time parameter, $\tau_{c}$, describing rotational motions of the water molecules $[30,35]$. For pure water that parameter reached $10^{-12} \mathrm{~s}$ and for ice it decreased to $10^{-6} \mathrm{~s}$ [55]. Such a broad range of $\tau_{\mathrm{c}}$ allows a detailed molecular analysis of pastes and similar systems.

$$
\begin{gathered}
\frac{1}{T_{1}}=\frac{6}{20} \frac{\mu_{0}^{2}}{16 \pi^{2}} \frac{\gamma^{4} \hbar^{2}}{r_{0}^{6}}\left[\frac{\tau_{\mathrm{c}}}{1+\left(\bar{\omega} \tau_{\mathrm{c}}\right)^{2}}+\frac{4 \tau_{\mathrm{c}}}{1+\left(2 \bar{\omega} \tau_{\mathrm{c}}\right)^{2}}\right] \\
\frac{1}{T_{2}}=\frac{3}{20} \frac{\mu_{0}^{2}}{16 \pi^{2}} \frac{\gamma^{4} \hbar^{2}}{r_{0}^{6}}\left[3 \tau_{\mathrm{c}}+\frac{5 \tau_{\mathrm{c}}}{1+\left(\bar{\omega} \tau_{\mathrm{c}}\right)^{2}}+\frac{2 \tau_{\mathrm{c}}}{1+\left(2 \bar{\omega} \tau_{\mathrm{c}}\right)^{2}}\right]
\end{gathered}
$$

As it can be seen in Figure 1, there were two mean correlation times for the HCS paste, that is, one related to bound water, s, and the other to bulk water, 1 . Changes of $\tau_{\mathrm{c}}$ over time in pastes of NCS and the $\mathrm{s}$ fraction of HCS had the same character. $\tau_{\mathrm{c}}$ for the $\mathrm{s}$ fraction was shorter indicating a more solid state character of this fraction. The l-fraction had a liquid character. Corresponding values of that parameter were lower than these for WCS. In the liquid fraction of HCS system, changes were observed during the first 10 days. Analysis of the changes in $\tau_{c}$ for pure corn starch pastes under study revealed that the changes proceeded in three characteristic periods. Initially, within a few days microviscosity of pastes of NCS and HCS declined. In the WCS paste such an effect did not appear. Thus, a conclusion could be drawn that amylose chains had the greatest effect on short-time changes. Within 30 subsequent days molecular dynamics of water in every paste changed the most significantly regardless of the starch variety. They were most remarkable in the paste of NCS and in the s-fraction of the WCS paste. Changes in the 1-faction of the latter paste were subtle. On storage longer than 30 days, the network structures stabilized.

Figure 2 presents changes of mean correlation times in binary pastes of the NCS-hydrocolloid pastes. 


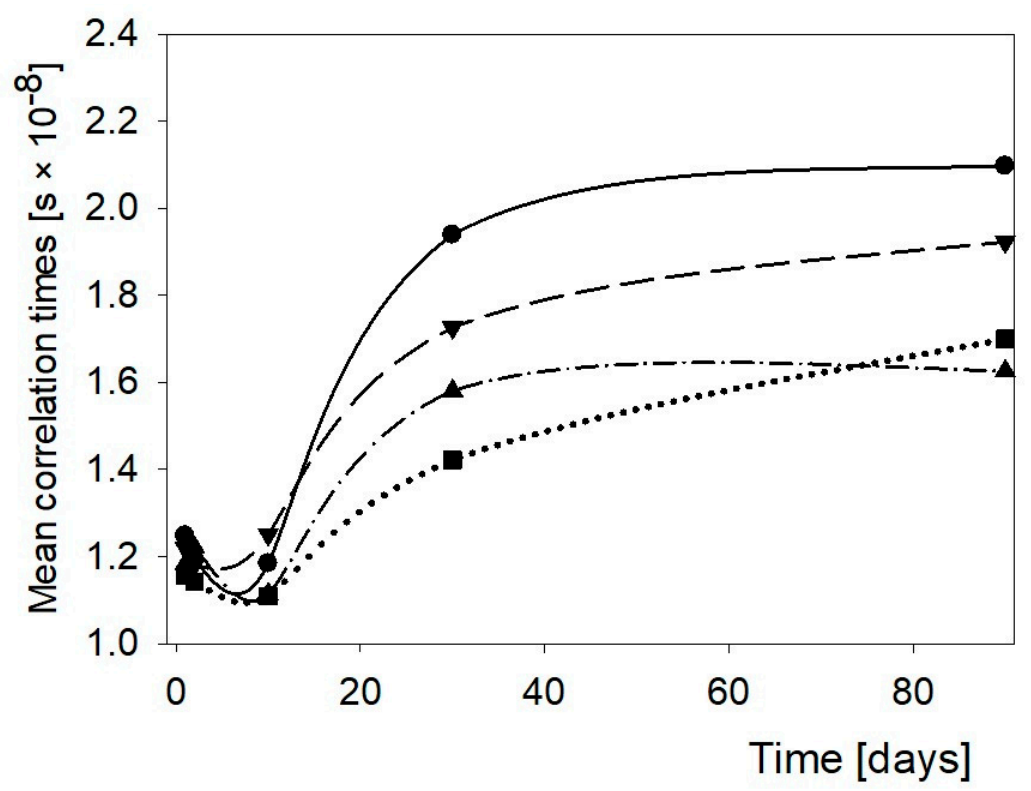

Figure 2. Changes of the mean correlation times of NCS paste and its binary mixtures with hydrocolloids. - - NCS, $\mathbf{v}-\mathrm{NCS}+\mathrm{AG}, \mathbf{\square}-\mathrm{NCS}+\mathrm{GG}$, and $\mathbf{\Delta}-\mathrm{NCS}+\mathrm{XG}$.

Mean correlation times always decreased after admixing a hydrocolloid and that effect was observed within whole storage period. It resulted from repulsing water from the system in which interaction between starch and water was replaced with interactions of starch with hydrocolloid. The course of the time dependent changes in the binary pastes was similar. The minimum $\tau_{\mathrm{c}}$ was observed within the first 2-10 days of storage. It could be associated with short-time retrogradation of starch in pastes with simultaneous repulsion of water out of the network. After approximately 10 days, $\tau_{\mathrm{c}}$ rose considerably. Proceeding binding of water in the structure of the polymeric network hindered rotational motions of the water molecules. Admixed hydrocolloids significantly decreased the role of that effect. GG appeared the least efficient in that respect. Thus, the addition of this gum to NCS paste proved the most efficient. However, on prolonged storage, $\tau_{c}$ increased in this paste, which suggests that GG bound water even after retrogradation was completed. XG and AG also interacted with starch in the relevant pastes repulsing water from the network but on extended time they had no effect on the molecular dynamics of water.

Effect of hydrocolloids upon molecular dynamics of water in WCS pastes is presented in Figure 3. Within first 10 days the changes were similar. Among hydrocolloids, GG was the most efficient in inhibiting molecular motions of water. During prolonged storage, $\tau_{\mathrm{c}}$ rose considerably in this binary paste. Simultaneously, in contrast to the NCS paste, the structure of the network of the WCS paste developed successively which suppressed the mobility of water molecules. The presence of GG intensified formation of the solid state structure. Both of the other hydrocolloids decreased $\tau_{c}$ as they provided more freedom for the rotational motions. Likely, both these hydrocolloids hindered retrogradation of amylopectin and AG was particularly efficient in this respect.

Time dependent changes of water mobility in the binary HCS-hydrocolloid pastes are demonstrated in Figure 4. Effect of hydrocolloid was the most potent within the initial few days. The addition of the hydrocolloids resulted in decreased microviscosity of the fraction of bulk water of the polymeric systems. The effect was the strongest when XG was introduced. After 30 days the effect of hydrocolloids cased. Initially, the water mobility of the bound water fraction in the HCS pastes was hindered by AG and GG. $\tau_{\mathrm{c}}$ reached certain minima within the first 10 days, which suggests an essential role of both hydrocolloids in the short-term retrogradation of amylose. After approximately 30 days, a further decrease in $\tau_{\mathrm{c}}$ for all systems was observed. It could point to changes in the amylose 
network. The polymer-polymer interactions repulsed water out of that network. Only GG disturbed that process.

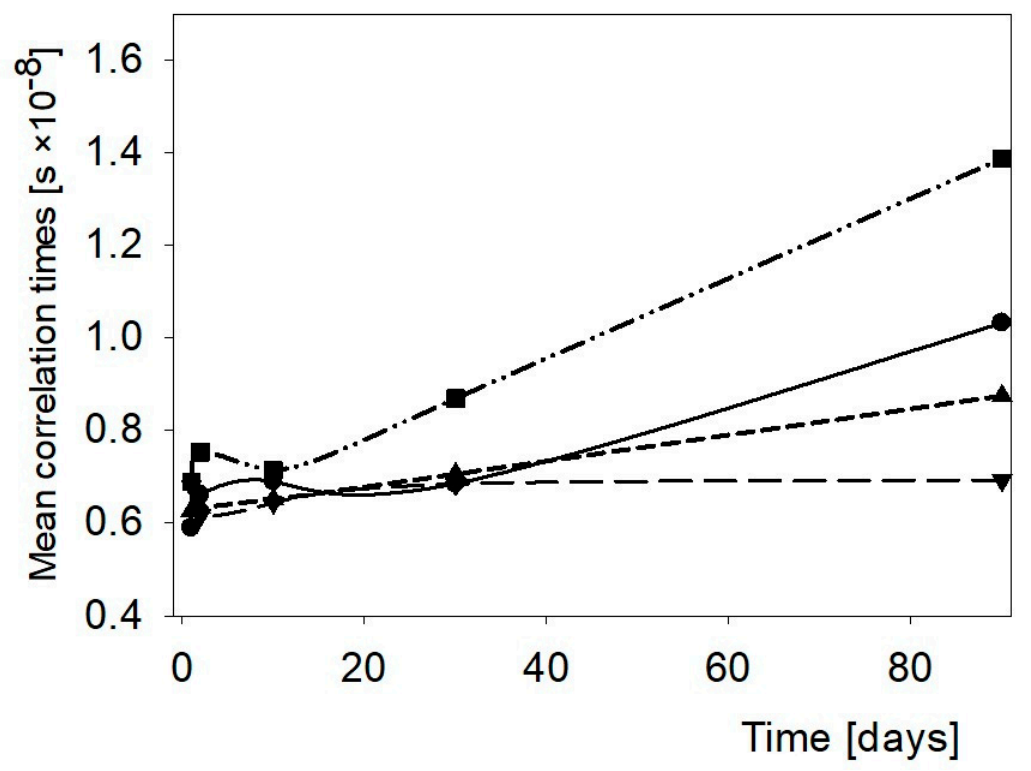

Figure 3. Changes of the mean correlation times in the WCS paste and the WCS binary pastes with

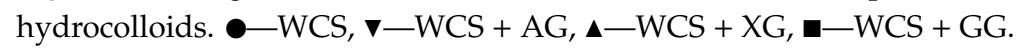

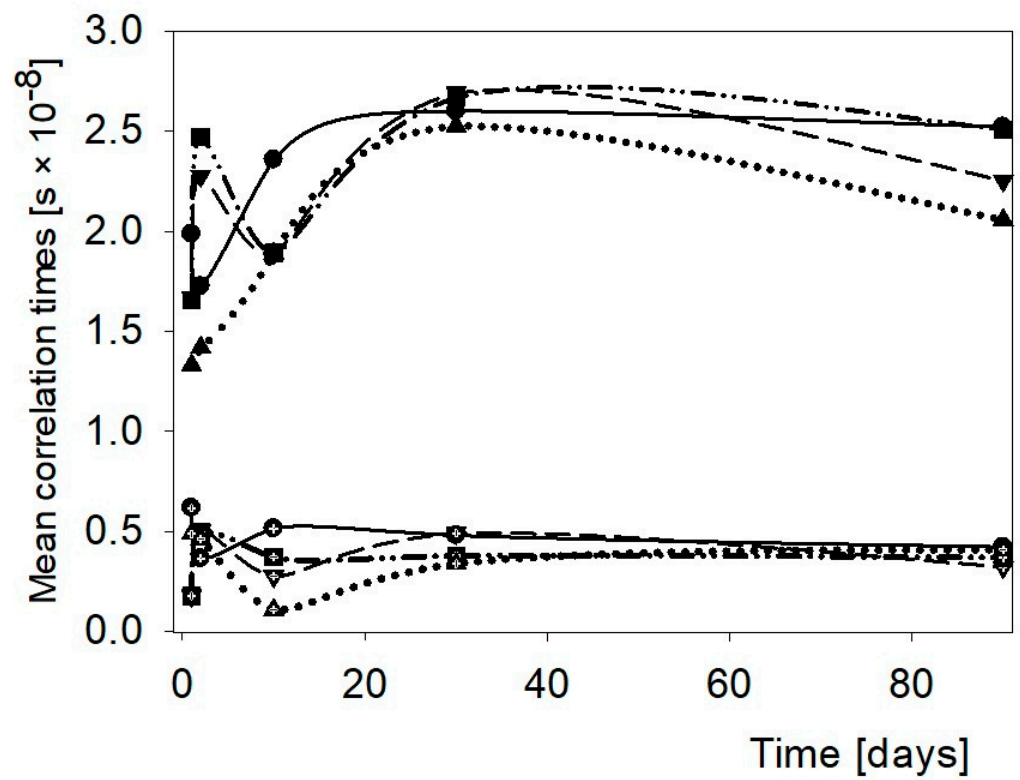

Figure 4. Changes of the mean correlation times in the HCS paste and the HCS binary pastes with hydrocolloids. - - HCS, $\mathbf{v}-\mathrm{HCS}+\mathrm{AG}, \mathbf{\Delta}-\mathrm{HCS}+\mathrm{XG}$, and $\mathbf{\bullet - H C S}+\mathrm{GG}$.

\section{Conclusions}

Pastes of starch with high amylose content (approximately 50\%) contained two different fractions of water molecules. They were these bound to amylose and amylopectin, respectively. The water molecules of the s-fraction (the fraction of bound water) were characterized by long mean correlation times. These times were an order of magnitude higher than those of the l-fraction. Thus, amylose was found to be responsible for the formation of the polymeric network. The amylopectin fraction (l-fraction) controlled the mobility of water in the pastes to a much lesser extent and it had a minor influence on the formation of network. This conclusion was based on the short mean correlation time 
values on the one hand and small differences (of approximately 25\%) observed between the first and the 90th day of storage on the other.

Normal and waxy corn starches formed compact structures on prolonged storage only. Elevated content of amylose accelerated the formation of such structure. Initially polymer-polymer interactions dominated. They manifested themselves through times of the spin-spin relaxation shortened by $40-60 \%$.

The amount of bound water increased with the amylose content in the system. An increase in $T_{1}$ relaxation time was observed from 1401 to $1612 \mathrm{~ms}$ for pastes containing $50 \%$ to $99 \%$ amylose in starch. Hydrocolloids in the pastes shortened mean correlation times within the first ten days of storage. Thus, binary pastes had lower microviscosity than the pastes of pure starches. During retrogradation of amylopectin, Arabic and xanthan gums hindered the formation of solid phase structures. This was indicated by a $20-40 \%$ increase of mean correlation time values during 90 days of storage. Guar gum, in contrast, evoked an increase in mean correlation times in a prolonged process of changes of molecular dynamics of water. It was caused by a continued expansion of the polymeric network. The $\tau_{\mathrm{c}}$ parameter, calculated on the basis basic parallel processes (BPP) equations, allowed the analysis of changes of water mobility in the studied polymeric systems.

Author Contributions: Investigation, M.S., M.K., A.D., P.T., K.W., Ł.M., P.Ł.K. and H.M.B.; Methodology, M.S. and H.M.B.; Writing—original draft, M.S., M.K., A.D., P.Ł.K. and H.M.B.; Writing一review and editing, P.Ł.K., H.M.B.

Funding: This project was financed from the funds of the National Science Centre of Poland awarded basing on the decision number UMO-2013/11/B/NZ9/01951.

Conflicts of Interest: The authors declare no conflict of interest.

\section{References}

1. Makowska, A.; Szwengiel, A.; Kubiak, P.; Tomaszewska-Gras, J. Characteristics and structure of starch isolated from triticale. Starch Stärke 2014, 66, 895-902. [CrossRef]

2. Lewandowicz, J.; Le Thanh-Blicharz, J. Quality of reduced fat mayonnaise prepared with native waxy starches. In Proceedings of the 14th International Conference on Polysaccharides-Glycoscience, Prague, Czech Republic, 7-9 November 2018; Rapkova, R., Hinkova, A., Copikova, J., Sarka, E., Eds.; Czech Chemical Society: Prague, Czech Republic, 2018; pp. 262-265.

3. Zobel, H.F.; Stephen, A.M. Starch: Structure, analysis, and application. In Food Polysaccharides and Their Applications; Stephen, A.M., Phillips, G.O., Eds.; CRC Press: Boca Raton, FL, USA, 2016; pp. 25-85. ISBN 9780429116162.

4. Kennedy, H.M. Starch- and Dextrin-Based Adhesives. In Adhesives from Renewable Resources; ACS Publication: Washington, DC, USA, 1989; pp. 326-336.

5. Jeżowski, P.; Kowalczewski, P.Ł. Starch as a Green Binder for the Formulation of Conducting Glue in Supercapacitors. Polymers (Basel) 2019, 11, 1648. [CrossRef] [PubMed]

6. Russell, P.L. The ageing of gels from starches of different amylose/amylopectin content studied by differential scanning calorimetry. J. Cereal Sci. 1987, 6, 147-158. [CrossRef]

7. Yu, S.; Zhang, Y.; Ge, Y.; Zhang, Y.; Sun, T.; Jiao, Y.; Zheng, X.-Q. Effects of Ultrasound Processing on the Thermal and Retrogradation Properties of Nonwaxy Rice Starch. J. Food Process Eng. 2013, 36, 793-802. [CrossRef]

8. Liu, H.; Yu, L.; Xie, F.; Chen, L. Gelatinization of cornstarch with different amylose/amylopectin content. Carbohydr. Polym. 2006, 65, 357-363. [CrossRef]

9. Le Thanh-Blicharz, J.; Lubiewski, Z.; Voelkel, E.; Lewandowicz, G. Evaluation of rheological properties of commercial native starches. Zywnosc Nauka Technol. Jakosc/Food Sci. Technol. Qual. 2011, 18, 53-65. [CrossRef]

10. Jouppila, K.; Kansikas, J.; Roos, Y.H. Factors affecting crystallization and crystallization kinetics in amorphous corn starch. Carbohydr. Polym. 1998, 36, 143-149. [CrossRef]

11. Fredriksson, H.; Björck, I.; Andersson, R.; Liljeberg, H.; Silverio, J.; Eliasson, A.-C.; Åman, P. Studies on $\alpha$-amylase degradation of retrograded starch gels from waxy maize and high-amylopectin potato. Carbohydr. Polym. 2000, 43, 81-87. [CrossRef]

12. Peterson, S.C.; Eller, F.J.; Fanta, G.F.; Felker, F.C.; Shogren, R.L. Effects of critical fluid lipid extraction on the gelatinization and retrogradation of normal dent cornstarch. Carbohydr. Polym. 2007, 67, 390-397. [CrossRef] 
13. Sandhu, K.; Singh, N. Some properties of corn starches II: Physicochemical, gelatinization, retrogradation, pasting and gel textural properties. Food Chem. 2007, 101, 1499-1507. [CrossRef]

14. Ronda, F.; Roos, Y.H. Gelatinization and freeze-concentration effects on recrystallization in corn and potato starch gels. Carbohydr. Res. 2008, 343, 903-911. [CrossRef] [PubMed]

15. Liu, Q.; Thompson, D.B. Effects of moisture content and different gelatinization heating temperatures on retrogradation of waxy-type maize starches. Carbohydr. Res. 1998, 314, 221-235. [CrossRef]

16. Liu, Q.; Thompson, D.B. Retrogradation of du wx and su2 wx Maize Starches After Different Gelatinization Heat Treatments. Cereal Chem. J. 1998, 75, 868-874. [CrossRef]

17. Chang, Y.-H.; Lin, J.-H. Effects of molecular size and structure of amylopectin on the retrogradation thermal properties of waxy rice and waxy cornstarches. Food Hydrocoll. 2007, 21, 645-653. [CrossRef]

18. Park, E.Y.; Baik, B.-K.; Lim, S.-T. Influences of temperature-cycled storage on retrogradation and in vitro digestibility of waxy maize starch gel. J. Cereal Sci. 2009, 50, 43-48. [CrossRef]

19. Cai, L.; Shi, Y.-C. Structure and digestibility of crystalline short-chain amylose from debranched waxy wheat, waxy maize, and waxy potato starches. Carbohydr. Polym. 2010, 79, 1117-1123. [CrossRef]

20. Fisher, D.K.; Thompson, D.B. Retrogradation of Maize Starch After Thermal Treatment Within and Above the Gelatinization Temperature Range. Cereal Chem. J. 1997, 74, 344-351. [CrossRef]

21. Liu, H.; Yu, L.; Chen, L.; Li, L. Retrogradation of corn starch after thermal treatment at different temperatures. Carbohydr. Polym. 2007, 69, 756-762. [CrossRef]

22. Von Borries-Medrano, E.; Jaime-Fonseca, M.R.; Aguilar-Méndez, M.A.; García-Cruz, H.I. Addition of galactomannans and citric acid in corn starch processed by extrusion: Retrogradation and resistant starch studies. Food Hydrocoll. 2018, 83, 485-496. [CrossRef]

23. Niu, H.; Han, Q.; Cao, C.; Liu, Q.; Kong, B. Short-term retrogradation behaviour of corn starch is inhibited by the addition of porcine plasma protein hydrolysates. Int. J. Biol. Macromol. 2018, 115, 393-400. [CrossRef]

24. Niu, H.; Zhang, M.; Xia, X.; Liu, Q.; Kong, B. Effect of porcine plasma protein hydrolysates on long-term retrogradation of corn starch. Food Chem. 2018, 239, 172-179. [CrossRef] [PubMed]

25. Wang, L.; Xu, J.; Fan, X.; Wang, Q.; Wang, P.; Zhang, Y.; Cui, L.; Yuan, J.; Yu, Y. Effect of disaccharides of different composition and linkage on corn and waxy corn starch retrogradation. Food Hydrocoll. 2016, 61, 531-536. [CrossRef]

26. Wang, L.; Xu, J.; Fan, X.; Wang, Q.; Wang, P.; Yuan, J.; Yu, Y.; Zhang, Y.; Cui, L. The effect of branched limit dextrin on corn and waxy corn gelatinization and retrogradation. Int. J. Biol. Macromol. 2018, 106, 116-122. [CrossRef] [PubMed]

27. Dobosz, A.; Sikora, M.; Krystyjan, M.; Tomasik, P.; Lach, R.; Borczak, B.; Berski, W.; Lukasiewicz, M. Shortand long-term retrogradation of potato starches with varying amylose content. J. Sci. Food Agric. 2019, 99, 2393-2403. [CrossRef]

28. Dobosz, A.; Sikora, M.; Krystyjan, M. Retrogradation of starch with and without non-starch polysaccharide hydrocolloids added-Measurement methods and application thereof. Zywnosc Nauka Technol. Jakosc/Food Sci. Technol. Qual. 2014, 21, 5-20. [CrossRef]

29. Baranowska, H.M.; Sikora, M.; Dobosz, A.; Krystyjan, M.; Tomasik, P. Retrogradation process of waxy-starches gels without and with gum Arabic investigates by using $1 \mathrm{H}$ NMR method. In Proceedings of the The 9th International Conference on Starch Technology, Bangkok, Thailand, 27-28 February 2017.

30. Stangierski, J.; Baranowska, H.M. The Influence of Heating and Cooling Process on the Water Binding in Transglutaminase-Modified Chicken Protein Preparation, Assessed Using Low-Field NMR. Food Bioprocess Technol. 2015, 8, 2359-2367. [CrossRef]

31. Kowalczewski, P.Ł.; Walkowiak, K.; Masewicz, Ł.; Bartczak, O.; Lewandowicz, J.; Kubiak, P.; Baranowska, H.M. Gluten-Free Bread with Cricket Powder-Mechanical Properties and Molecular Water Dynamics in Dough and Ready Product. Foods 2019, 8, 240. [CrossRef]

32. Makowska, A.; Baranowska, H.M.; Michniewicz, J.; Chudy, S.; Kowalczewski, P.Ł. Triticale extrudates - Changes of macrostructure, mechanical properties and molecular water dynamics during hydration. J. Cereal Sci. 2017, 74, 250-255. [CrossRef]

33. Bloembergen, N.; Purcell, E.M.; Pound, R.V. Relaxation Effects in Nuclear Magnetic Resonance Absorption. Phys. Rev. 1948, 73, 679-712. [CrossRef]

34. Belton, P.S. NMR of Food Biopolymers. In Advances in Magnetic Resonance in Food Science; Elsevier: Amsterdam, The Netherlands, 1999; pp. 115-125. 
35. Tang, H.; Belton, P.S. Proton Relaxation in Plant Cell Walls and Model Systems. In Advances in Magnetic Resonance in Food Science; Elsevier: Amsterdam, The Netherlands, 1999; pp. 166-184.

36. Gibiński, M.; Kowalski, S.; Sady, M.; Krawontka, J.; Tomasik, P.; Sikora, M. Thickening of sweet and sour sauces with various polysaccharide combinations. J. Food Eng. 2006, 75, 407-414. [CrossRef]

37. Kowalski, S.; Sikora, M.; Tomasik, P.; Krystyjan, M. Starch polysaccharide hydrocolloid gels. Polimery 2008, 53, 457-464. [CrossRef]

38. Sikora, M.; Kowalski, S.; Tomasik, P. Binary hydrocolloids from starches and xanthan gum. Food Hydrocoll. 2008, 22, 943-952. [CrossRef]

39. Baranowska,H.; Sikora, M.; Kowalski, S.; Tomasik, P. Interactions of potato starch with selected polysaccharide hydrocolloids as measured by low-field NMR. Food Hydrocoll. 2008, 22, 336-345. [CrossRef]

40. Sikora, M.; Krystyjan, M.; Tomasik, P.; Krawontka, J. Mixed pastes of starches with guar gum. Polimery 2010, 55, 582-590. [CrossRef]

41. Baranowska, H.M.; Sikora, M.; Krystyjan, M.; Tomasik, P. Analysis of the formation of starch — hydrocolloid binary gels and their structure based on the relaxation times of the water molecules. Polimery 2011, 56, 478-483. [CrossRef]

42. Baranowska, H.M.; Sikora, M.; Krystyjan, M.; Tomasik, P. Evaluation of the time-dependent stability of starch-hydrocolloid binary gels involving NMR relaxation time measurements. J. Food Eng. 2012, 109, 685-690. [CrossRef]

43. Krystyjan, M.; Adamczyk, G.; Sikora, M.; Tomasik, P. Long-term storage stability of selected potato starch-Non-starchy hydrocolloid binary gels. Food Hydrocoll. 2013, 31, 270-276. [CrossRef]

44. Sikora, M.; Dobosz, A.; Krystyjan, M.; Adamczyk, G.; Tomasik, P.; Berski, W.; Kutyła-Kupidura, E.M. Thixotropic properties of the normal potato starch-Locust bean gum blends. LWT 2017, 75, 590-598. [CrossRef]

45. Fukushima, E.; Roeder, S.B.W. Experimental Pulse NMR. A Nuts and Bolts Approach; Addison-Wesley Publishing Company: London, UK, 1981.

46. Weglarz, W.P.; Haranczyk, H. Two-dimensional analysis of the nuclear relaxation function in the time domain: The program CracSpin. J. Phys. D Appl. Phys. 2000, 33, 1909-1920. [CrossRef]

47. Carr, H.Y.; Purcell, E.M. Effects of Diffusion on Free Precession in Nuclear Magnetic Resonance Experiments. Phys. Rev. 1954, 94, 630-638. [CrossRef]

48. Meiboom, S.; Gill, D. Modified Spin-Echo Method for Measuring Nuclear Relaxation Times. Rev. Sci. Instrum. 1958, 29, 688-691. [CrossRef]

49. Baranowska, H.M. Water Molecular Properties in Forcemeats and Finely Ground Sausages Containing Plant Fat. Food Biophys. 2011, 6, 133-137. [CrossRef]

50. Miklos, R.; Mora-Gallego, H.; Larsen, F.H.; Serra, X.; Cheong, L.-Z.; Xu, X.; Arnau, J.; Lametsch, R. Influence of lipid type on water and fat mobility in fermented sausages studied by low-field NMR. Meat Sci. 2014, 96, 617-622. [CrossRef] [PubMed]

51. Glöggler, S.; Blümich, B.; Appelt, S. NMR Spectroscopy for Chemical Analysis at Low Magnetic Fields. In Modern NMR Methodology; Springer: Berlin/Heidelberg, Germany, 2011; pp. 1-22.

52. Cameron, I.; Fullerton, G. Properties and size of multiple non-bulk water fractions on proteins and in cells. Water 2014, 4, 76-90. [CrossRef]

53. Baranowska, H.M.; Rezler, R. Emulsions stabilized using potato starch. Food Sci. Biotechnol. 2015, 24, 1187-1191. [CrossRef]

54. Baranowska, H.M.; Rezler, R. Water binding analysis of fat-water emulsions. Food Sci. Biotechnol. 2015, 24, 1921-1925. [CrossRef]

55. Coyle, F.M.; Martin, S.J.; McBrierty, V.J. Dynamics of water molecules in polymers. J. Mol. Liq. 1996, 69, 95-116. [CrossRef]

(C) 2019 by the authors. Licensee MDPI, Basel, Switzerland. This article is an open access article distributed under the terms and conditions of the Creative Commons Attribution (CC BY) license (http://creativecommons.org/licenses/by/4.0/). 